\title{
INCLUSÃO DE ALUNOS COM DEFICIÊNCIA NOS CURSOS DE GRADUAÇÃO DA UNIVERSIDADE FEDERAL DO TRIÂNGULO MINEIRO (UFTM)
}

\author{
INCLUSION OF DISABLED STUDENTS IN THE UNDERGRADUATE COURSES OF \\ UNIVERSIDADE FEDERAL DO TRIÂNGULO MINEIRO (UFTM)
}

\section{INCLUSIÓN DE ESTUDIANTES CON DISCAPACIDAD EN LOS CURSOS SUPERIORES DE LA UNIVERSIDADE FEDERAL DO TRIÂNGULO MINEIRO (UFTM)}

Camila Cunha Oliveira Giordani E-mail: camila.giordani@uftm.edu.br Liliane Carla Campos

E-mail: liliane.campos@uftm.edu.br Eliana Helena Correa Neves Salge E-mail: eliana.salge@uftm.edu.br Giselle Abreu de Oliveira

E-mail: giselle.oliveira@uftm.edu.br Diego de Morais Batista

E-mail: diego.batista@uftm.edu.br

Universidade Federal do Triângulo Mineiro - UFTM

\section{RESUMO}

Este artigo apresenta a análise de políticas públicas educacionais e ações institucionais voltadas para a inclusão de alunos com deficiência no âmbito dos cursos de graduação da Universidade Federal do Triângulo Mineiro (UFTM), em Uberaba-MG. Objetiva fomentar a compreensão acerca do processo de inclusão das Pessoas com Deficiência (PcD) para acesso e permanência com qualidade no ensino superior, visando ao sucesso escolar. Trata-se de uma pesquisa qualitativa, que utiliza fontes de caráter bibliográfico e documental e apresenta ações institucionais voltadas para a assistência estudantil e o atendimento dos alunos com deficiência. Os resultados da investigação apontam que a UFTM, apesar de todos os avanços na busca de condições adequadas para o desenvolvimento integral dos diferentes acadêmicos, dentre eles os alunos com deficiência, necessita que sejam ampliados os recursos de natureza humana, orçamentária, físico-estruturais, tecnológica, formativa e pedagógica. O estudo pretende contribuir para reflexões e discussões sobre a importância de se universalizar, para os estudantes com deficiência, o acesso ao ensino de qualidade, via práticas educativas que respeitem a diversidade humana em todos os seus aspectos.

PALAVRAS-CHAVE: Inclusão Educacional. Aluno com Deficiência. Políticas Públicas em Educação.

\section{ABSTRACT}

This paper presents an analysis of public policies and institutional actions aimed at the inclusion of students with disabilities in the scope of undergraduate courses at the Universidade Federal do Triangulo Mineiro (UFTM), in Uberaba-MG. It aims to promote understanding about the inclusion process of people with disabilities $(P w D)$ for access and permanence with quality in higher education, specific to school success. It is a qualitative research, which uses bibliographic and documentary sources and presents institutional actions aimed at student assistance and the support of students with disabilities. The results of the investigation indicate that UFTM, despite all the advances in the search for combined conditions for the integral development of different academics, among them students with disabilities, need to expand the human, budgetary, physical- 


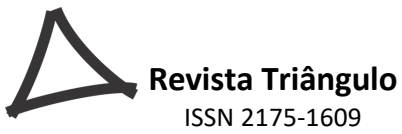

touch resources, technological, training and pedagogical. The study aims to contribute to reflections and exercise on the importance of universalizing, for students with disabilities, access to quality education, through educational practices that respect human diversity in all its aspects.

KEYWORDS: Educational Inclusion. Disabled Student. Public Policies in Education.

\section{RESUMEN}

Este artículo presenta el análisis de las políticas públicas educativas y las acciones institucionales dirigidas a la inclusión de estudiantes con discapacidad en el ámbito de los cursos superiores de la Universidade Federal do Triângulo Mineiro (UFTM), en Uberaba-MG. Tiene como objetivo fomentar la comprensión sobre el proceso de inclusión de Personas con Discapacidad para el acceso y permanencia con calidad en la educación superior, con miras al éxito escolar. Se trata de una investigación cualitativa, que utiliza fuentes de carácter bibliográfico $y$ documental y presenta acciones institucionales dirigidas a la atención y asistencia estudiantil a estudiantes con discapacidad. Los resultados de la investigación muestran que la UFTM, a pesar de todos los avances en la búsqueda de condiciones adecuadas para el desarrollo integral de diferentes académicos, entre ellos estudiantes con discapacidad, necesita ampliar los recursos humanos, presupuestarios, fisico-estructurales, tecnológicos, formativa y pedagógica. El estudio tiene como objetivo contribuir a las reflexiones y debates sobre la importancia del acceso universal a una educación de calidad para los estudiantes con discapacidad, a través de prácticas educativas que respeten la diversidad humana en todos sus aspectos.

PALABRAS-CLAVE: Inclusión Educativa. Estudiantes con Discapacidades. Políticas Públicas en Educación.

\section{INTRODUÇÃO}

As temáticas ligadas à educação especial têm sido amplamente debatidas por integrarem um dos maiores desafios a serem enfrentados pelo sistema educacional moderno: a escola para todos. A universalização do acesso à educação evidenciou a necessidade de se repensar as instituições escolares, a fim de que sujeitos antes excluídos dos processos formais de aprendizagem possam ter acesso e garantia de permanência, com qualidade, nestas instituições.

Considerando o processo histórico de exclusão escolar sofrido pelas Pessoas com Deficiência $(\mathrm{PcD})$, as políticas públicas brasileiras referentes à educação especial buscam reverter este quadro e criar condições para melhorar a qualidade do ensino ofertado. No entanto, apesar de a educação especial ter alcançado o status de direito inquestionável, ainda há um longo caminho para que se consiga materializar uma política de educação democrática, plural e, de fato, inclusiva.

São inúmeros os obstáculos encontrados pelas $\mathrm{PcD}$, perpassando desde problemas estruturais no espaço escolar até a falta de formação adequada dos profissionais da educação. Apesar disso, vem crescendo o número de alunos com deficiência que concluem a educação básica e conseguem ingressar no ensino superior. Dados do Censo da Educação Superior de 
2017 apontam um crescimento de cerca de 86\% no número de matrículas de pessoas com deficiência, transtornos globais do desenvolvimento ou altas habilidades em cursos superiores de instituições brasileiras públicas e privadas, também em virtude da implementação da política de cotas para acesso ao ensino superior. Este público totalizou 38.272 matrículas, das quais $38 \%$ foram ocupadas por pessoas com deficiência física, $28 \%$ por pessoas com baixa visão, $14 \%$ por pessoas com deficiência auditiva, $6 \%$ por pessoas cegas, $6 \%$ por pessoas surdas e $8 \%$ pelas demais deficiências, síndromes e transtornos.

Neste contexto, a presente pesquisa toma como objeto a realidade da Universidade Federal do Triângulo Mineiro (UFTM), a fim de verificar e compreender as políticas e as ações que vêm sendo desenvolvidas com foco na inclusão de alunos com deficiência em seus cursos de graduação.

\section{OBJETIVOS E METODOLOGIA}

Com o objetivo de fomentar a compreensão acerca do processo de inclusão das PcD para acesso e permanência, com qualidade, no ensino superior, visando ao sucesso escolar discente, analisou-se as políticas públicas educacionais e as ações institucionais voltadas para a inclusão de alunos com deficiência no âmbito dos cursos de graduação da UFTM, no campus sede, localizado na cidade de Uberaba-MG ${ }^{1}$.

Para tanto, foi feito um estudo de natureza qualitativa, com fontes documentais e bibliográficas. Nessa direção, foram objetos de investigação documental os seguintes instrumentos normativos da UFTM: Estatuto; Projeto de Desenvolvimento Institucional (PDI); Projeto Pedagógico Institucional (PPI); Projetos Pedagógicos dos Cursos de Graduação (PPC), dentre outros documentos institucionais que abordam a temática da inclusão de PcD, na condição de alunos. Para a pesquisa bibliográfica, buscou-se, em especial, referências nas legislações educacionais relativas ao ensino superior, que abordam a educação especial na perspectiva da inclusão.

\section{RESULTADOS E ANÁLISES}

\section{Políticas nacionais de inclusão das PcD nas IFES}




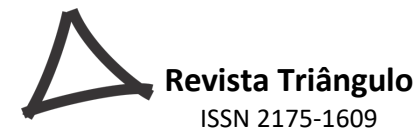

As ações voltadas às pessoas com deficiência nas Instituições Federais de Ensino Superior (IFES) englobam as chamadas propostas de inclusão e assistência estudantil, que ganharam impulso nos últimos anos, visando garantir o acesso e a permanência de alunos com deficiência nas instituições, bem como de alunos com baixa renda e outros fatores que configurem vulnerabilidade e desvantagens frente ao processo de ensino-aprendizagem. Tais propostas nasceram, principalmente, do reconhecimento das mudanças no perfil socioeconômico dos alunos do ensino superior, tendo em vista a ampliação do acesso às IFES, conforme constatado pelo Fórum Nacional de Pró-reitores de Assuntos Comunitários e Estudantis, em 2004. Os estudos feitos no âmbito do referido Fórum buscaram encontrar formas de reduzir as taxas de retenção e evasão nas IFES, bem como fortalecer o processo de democratização do acesso, permanência e conclusão do ensino superior.

Nesse aspecto, no ano de 2005, foi lançado o Programa Incluir, como iniciativa da Secretaria de Educação Superior (SESU) e da Secretaria de Educação Continuada, Alfabetização, Diversidade e Inclusão (SECADI), tendo como objetivo principal a implementação de uma política de acessibilidade de pessoas com deficiência no ensino superior. Até 2011, o programa materializava-se por meio de chamadas públicas que permitiam a formulação de estratégias para superação das barreiras impostas ao acesso das pessoas com deficiência ao ensino superior. Já a partir de 2012, o programa foi universalizado, passando a atender a todas as IFES, instigando-as à elaboração de políticas e ações de acessibilidade ampa e articulada.

Ainda no âmbito do acesso de $\mathrm{PcD}$ ao ensino superior, destaca-se a Convenção sobre os Direitos das Pessoas com Deficiência, aprovada pela ONU em 13 de dezembro de 2006. A convenção estabeleceu que os países signatários - dentre os quais o Brasil fez parte deveriam assegurar um sistema de educação inclusiva em todos os níveis de ensino, de modo a promover a plena participação e a inclusão, adotando medidas para assegurar o acesso de pessoas com deficiência ao ensino superior e outras formas de ensino, sem discriminação e com igualdade de condições.

Na esteira dessas concepções, o Programa de Apoio a Planos de Reestruturação e Expansão das Universidades Federais (REUNI), instituído pelo Decreto n. ${ }^{\text {o }}$ 6.096/2007, objetivou "criar condições para a ampliação do acesso e permanência na educação superior, no nível de graduação, pelo melhor aproveitamento da estrutura física e de recursos humanos existentes nas universidades federais" (BRASIL, 2007a, p.1.). Dentre suas diretrizes, destaca- 
se a "ampliação de políticas de inclusão e assistência estudantil” (BRASIL, 2007a, p.1), que estão

diretamente associadas à inclusão, democratização do acesso e permanência, de forma a promover a efetiva igualdade de oportunidades, compreendida como parte integrante de um projeto de nação (BRASIL, 2007b, p.6).

Esta perspectiva ganhou destaque no documento Diretrizes Gerais do REUNI (2007), que orientou as IFES a explicitarem seu compromisso social por meio de políticas de inclusão, programas de assistência estudantil e políticas de extensão universitária.

No mesmo ano, 2007, foi lançado o Plano de Desenvolvimento da Educação (PDE), que objetivava, dentre outras questões, o acesso e a permanência das pessoas com deficiência na educação superior. Ainda em 2007, a Associação Nacional dos Dirigentes das Instituições Federais de Ensino Superior (ANDIFES) apresentou o Plano Nacional de Assistência Estudantil, reforçando a importância dos investimentos em políticas de inclusão no âmbito do ensino superior. Assim, o documento deu à assistência estudantil um caráter de direito e permitiu, por meio da Portaria Normativa n. ${ }^{0}$ 39, de 12 de dezembro de 2007, a criação do Programa Nacional de Assistência Estudantil (PNAES), definindo as seguintes áreas estratégicas: moradia estudantil, alimentação, transporte, assistência à saúde, inclusão digital, cultura, esporte, creche e apoio pedagógico, imprescindível à permanência de muitos alunos com deficiência no ensino superior.

Outros marcos legais e normativos fortaleceram o acesso e a permanência das pessoas com deficiência no ensino superior, como o Plano Nacional dos Direitos da Pessoa com Deficiência - Viver sem Limites, criado em 2011, visando garantir um sistema educacional inclusivo, a acessibilidade nos equipamentos públicos de educação, a qualificação e a capacitação profissional de pessoas com deficiência, dentre outros. Ainda, o Decreto n. ${ }^{\circ}$ 7.611, de 17 de novembro de 2011, que dispõe sobre a educação especial e o atendimento educacional especializado em todos os níveis de ensino; a Lei n. ${ }^{\circ} 12.764$, de 27 de dezembro de 2012, que trata da proteção dos direitos da pessoa com transtorno do espectro autista; o Decreto n. ${ }^{\circ}$ 5.626, de 22 de dezembro de 2005, que aborda a Língua Brasileira de Sinais (Libras) e determina que "a Libras deve ser inserida como disciplina curricular obrigatória nos cursos de formação de professores para o exercício do magistério, em nível médio e superior", bem como deve constituir-se "em disciplina curricular optativa nos demais cursos de educação superior" (BRASIL, 2005, s./p.). 
No ano de 2010, o Decreto n. ${ }^{\circ}$ 7.234, de 19 de julho de 2010, instituiu o Programa Nacional de Assistência Estudantil (PNAES), trazendo a necessidade de uma sistematização ainda maior da assistência estudantil nas IFES. O programa definiu como uma das ações da assistência estudantil o "acesso, participação e aprendizagem de estudantes com deficiência, transtornos globais do desenvolvimento e altas habilidades e superdotação" (BRASIL, 2010, s./p.).

Assim, a fim de afirmar o acesso de pessoas com deficiência no ensino superior e em outros níveis, a Lei n. ${ }^{\circ} 12.711$, de 29 de agosto de 2012, alterada pela Lei n. ${ }^{\circ} 13.409$, de 28 de dezembro de 2016, determinou que as IFES devem, no sistema de cotas, assegurar vagas para pessoas com deficiência, na mesma proporção existente entre pessoas com deficiência e a população total da unidade da federação onde está instalada a instituição. Desta forma, as IFES têm constituído comissões multidisciplinares, a fim de avaliarem as solicitações de ingresso por cota e garantir o cumprimento deste dispositivo legal.

\section{Políticas de inclusão na UFTM: ações, projetos e programas}

Assim como outras universidades brasileiras, a UFTM passou a se organizar para receber e garantir a permanência dos alunos com deficiência no ensino superior, de forma mais clara e sistemática, a partir de 2007, após a adesão ao Programa de Reestruturação e Expansão das Universidades Federais (REUNI). Entretanto, destacou em seu documento de adesão ao referido programa que, naquele momento, não havia instrumentos institucionais qualificados para avaliar a permanência dos alunos nos cursos, bem como não havia ações sistematizadas destinadas à assistência estudantil.

Para o enfrentamento da situação descrita, dentre outras ações, a Instituição implementou o Programa de Assistência Estudantil, que culminou na criação do Núcleo de Assistência Estudantil (NAE), composto por uma equipe multiprofissional que visava garantir condições para o atendimento das diversas áreas estratégicas da assistência estudantil, incluindo atenção à saúde, transporte e alimentação. O programa ganhou status de compromisso institucional essencial para a concretização da democratização do acesso e promoção da equidade no espaço universitário.

Em agosto de 2010, a UFTM deu um passo importante no que diz respeito à inclusão e assistência discente, criando a Pró-Reitoria de Assuntos Comunitários e Estudantis (PROACE), que atua até o presente momento e representa a inserção orgânica da assistência 
estudantil na estrutura da UFTM. Na época, o NAE passou a fazer parte desta Pró-reitoria, bem como foi criado, também, o Núcleo de Acessibilidade.

Nesse contexto, antes da criação da PROACE e de seu ambiente funcional "Núcleo de Acessibilidade", em 2010, a acessibilidade na UFTM já vinha se apresentando de forma tímida, sendo discutida em fóruns, grupos de trabalho, comissões e outros espaços, mas foi a partir dessa estrutura organizacional que as ações se tornaram mais efetivas e coordenadas.

Atualmente, a PROACE organiza-se por meio de departamentos estruturalmente articulados, a saber, o Departamento de Assistência Estudantil e Serviços à Comunidade, composto pelo Setor de Acessibilidade e pelo Setor de Auxílios a Estudantes; e a Divisão de Serviço Social, além dos ambientes funcionais Núcleo de Atenção Estudantil em Saúde e Serviço de Acompanhamento Pedagógico Discente.

De acordo com o regulamento da PROACE (Art.10), construído em 2016, compete ao Setor de Acessibilidade:

I - Atendimento de Tradução e Interpretação de Libras / Português;

II - Adaptação de materiais para arquivo digital acessível e/ou Braille para alunos cegos ou baixa visão;

III - Elaboração de editais de seleção de Tutoria Inclusiva para apoio à acessibilidade;

IV - Seleção e acompanhamento dos Tutores Inclusivos;

V - Capacitação dos tutores inclusivos e comunidade interna UFTM, no que se refere à lida com pessoas com deficiência;

VI - Cadastro e acompanhamento dos alunos com necessidades educacionais especiais na UFTM;

VII - Criação de projetos de sensibilização e minimização de barreiras atitudinais ${ }^{2}$;

VIII - Consultoria ao departamento responsável pela infraestrutura da UFTM visando melhorias na acessibilidade estrutural da UFTM;

IX - Criação e gerencia das salas de acessibilidade nas bibliotecas;

$X$ - Elaboração e gerenciamento de programas, projetos e ações de acessibilidade e inclusão (UNIVERSIDADE FEDERAL DO TRIÂNGULO MINEIRO, 2016, p.7).

Assim, para que essas competências possam ser efetivadas, a PROACE precisa da ampliação de recursos de natureza humana, orçamentária, tecnológica e físico-estruturais. Nessa direção, quanto aos recursos humanos, o Setor de Acessibilidade conta atualmente com apenas 5 (cinco) servidores, sendo um técnico em assuntos educacionais, um assistente em administração e três intérpretes de Libras. Ressalta-se que um dos intérpretes de LIBRAS 
desempenha também a função de chefia do setor e, necessariamente, utiliza parte de sua carga horária em questões de ordem administrativa e gerencial.

Os recursos orçamentários são basicamente oriundos do Programa Nacional de Assistência Estudantil - PNAES ${ }^{3}$ sendo parte referente ao Programa Incluir ${ }^{4}$ e parte referente ao Programa de Tutoria Inclusiva, estando distribuídos da seguinte forma: Orçamento de 2020 para o Programa de Tutoria Inclusiva: R\$ 34.000,00 (trinta e quatro mil reais); orçamento de 2020 do Programa Incluir (para investimentos do tipo consumo): R \$20.000,00 (vinte mil reais); orçamento de 2020 do Programa Incluir (para investimentos do tipo capital - aquisição de equipamentos/ material permanente): R \$10.000,00 (dez mil reais).

Quanto aos recursos tecnológicos, se referem aos principais e mais comuns e abrangentes recursos, geralmente voltados para pessoas com deficiência visual, como leitores de tela, leitores autônomos, máquina fusora de relevos, lupas eletrônicas e digitais, impressoras Braille, bengalas de rastreamento, modelos táteis, máquinas Braille Perkins e kits de reglete/punção. Busca-se, ainda, utilizar e apresentar aos usuários as tecnologias digitais acessíveis em computadores e dispositivos móveis, como dicionários interativos de Língua Brasileira de Sinais (LIBRAS), scanners autônomos, controle de mouse por movimentos da cabeça/olhos e outras funções de acessibilidade disponíveis nesses aparelhos, especialmente as gratuitas.

Estruturalmente, o setor conta com uma sala ampla, porém subdividida, situada no Centro Educacional da UFTM, sendo destinada ao trabalho dos servidores lotados no setor, ao ambiente de estudo de alunos atendidos e à atuação de Tutores Inclusivos, bem como à adaptação de material e acompanhamento dos alunos público-alvo do setor. Esse cenário dificulta a atuação do setor, por diversos aspectos, dentre os quais se destacam: falta de espaço apropriado para estudo dos alunos atendidos; falta de espaço adequado para acompanhamento dos alunos atendidos pelos tutores, uma vez que um grupo pode atrapalhar o outro; dificuldade de concentração para revisão do material didático adaptado, devido à grande circulação e comunicação no ambiente; falta de espaço que garanta mobilidade de cadeirantes. Entretanto, a despeito de suas limitações, o setor realiza os atendimentos necessários, potencializados por meio de programas, projetos e articulações de parcerias com outros setores da UFTM, especialmente os da PROACE, e com outras instituições, como o Instituto de Cegos do Brasil Central (ICBC), Instituto Federal de Educação, Ciência e 
Tecnologia do Triângulo Mineiro (IFTM) e Associação Nacional de Educadores Inclusivos (ANEI BRASIL).

Além das atividades realizadas sob demanda, como o acolhimento dos alunos atendidos, adaptação de material didático, tradução e interpretação de LIBRAS e orientações e elucidações quanto à acessibilidade e condições específicas dos alunos atendidos, dentre outros, três programas/projetos do Setor de Acessibilidade se destacam, sendo eles:

a) Programa de Tutoria Inclusiva: Instituído desde o ano de 2017, seleciona alunos voluntários, ou beneficiados com incentivo financeiro no valor de $\mathrm{R} \$ 250,00$ (duzentos e cinquenta reais), que queiram atuar como Tutores Inclusivos junto a alunos com deficiência e/ou NEE. As atividades desempenhadas por esses tutores vão desde o auxílio aos alunos atendidos no transporte de seu material escolar para a sala de aula, até a adaptação de material pedagógico e acompanhamento funcional ao aluno durante as avaliações das disciplinas cursadas. Os tutores também participam de reuniões e debates a respeito dos desafios enfrentados cotidianamente e políticas de acessibilidade e inclusão.

b) Projeto Setembro Azul: Baseia-se em um evento composto por palestras e atividades realizadas com a comunidade surda da cidade de Uberaba/MG e região, valorizando sua língua e cultura, aproximando esse público da Universidade e os incentivando ao ingresso nos cursos ofertados.

c) Projeto Outros Olhos: Visa atuar na promoção da interação entre pessoas com deficiência nos espaços da UFTM, por meio de vivências realizadas com as demais pessoas de seu convívio. As vivências, embora geralmente referidas à cegueira, trabalham a valorização da diversidade e a sensibilização quanto a algumas das dificuldades enfrentadas pelas pessoas com deficiência e/ou NEE, combatendo assim barreiras atitudinais.

\section{Políticas de inclusão na UFTM: documentos institucionais}

Após apresentação da organização geral da UFTM para atendimento de $\mathrm{PcD}$, analisase, a seguir, o que os principais documentos institucionais - Estatuto, Plano de Desenvolvimento Institucional (PDI) e Projeto Pedagógico Institucional (PPI) - definem em relação à inclusão destes alunos.

\section{a) Estatuto da UFTM}




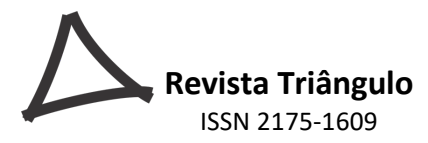

Na UFTM, o Estatuto é considerado a Carta Magna da universidade. Assim, o mesmo institui o perfil básico da instituição e suas diretrizes gerais de funcionamento, ordenando e orientando sua dinâmica operacional (UFTM, 2013). Nesse documento, estão previstos o perfil e a filosofia institucional, as formas de organização e de gestão da Universidade, a descrição da comunidade universitária, os recursos, os bens e o regime financeiro.

Em relação à temática inclusão, é relevante pontuar que este termo é explicitamente apresentado no Estatuto da UFTM apenas uma vez, no art. $7 .^{\circ}$, quando são apresentados os valores da instituição, tal como segue:

Art. 7. Constituem crenças fundamentais da Universidade, orientadoras, e inspiradoras da conduta, do sentimento e dos relacionamentos atinentes à comunidade universitária, caracterizando, por fim, seu caráter coletivo, os seguintes valores: [...] II - inclusão social [...] (UFTM, 2013 - grifo nosso).

A leitura do dispositivo acima nos permite inferir que a carta magna da UFTM não trata a inclusão das PcD de forma particular. A “inclusão social”, tal como é expressa no estatuto, refere-se à consideração e ao tratamento equânime da multiplicidade de sujeitos que compõem a comunidade acadêmica da UFTM, a partir do respeito às suas particularidades. Deste modo, todas as ações desenvolvidas na universidade devem incluir, além das PcD, negros, brancos, pardos, homens, mulheres, transgêneros, indígenas, dentre outras singularidades.

Nos demais itens do documento, a referência à inclusão é feita de forma implícita, reportando-se à importância da implementação de práticas e atitudes balizadas pelo princípio da igualdade, o qual pressupõe o tratamento isonômico entre indivíduos (tratar igualmente os iguais e desigualmente os desiguais, na exata medida de suas desigualdades).

Nesse sentido, destacamos o disposto no art. $8 .^{\circ}$, inciso II, segundo o qual a UFTM, dentre outras diretrizes, buscará "proporcionar a todos as mesmas oportunidades e condições de desenvolvimento intelectual e cultural" (UFTM, 2013, p.6). A referida diretriz, em certa medida, revela que a UFTM deve se orientar por normas e práticas permeadas pela compreensão de que a inclusão social e o tratamento isonômico ultrapassam as medidas que favorecem o acesso à Universidade.

b) Projeto de Desenvolvimento Institucional (PDI)

O PDI é o documento que expressa o planejamento estratégico da UFTM em termos de ações promotoras do desenvolvimento e da expansão universitária, em ciclos de cinco 
anos $^{5}$. Aprovado pela Resolução n. ${ }^{\text {o }}$ 3, de 16 de abril de 2013, do Conselho Universitário, o referido documento apresenta nove subdivisões. Na seção dedicada à apresentação da “Identidade Institucional” são expressos a Missão, Visão, Valores, Objetivos e as Diretrizes fundamentais da UFTM. Especificamente nos itens "Valores" e "Diretrizes Fundamentais" são reforçadas as disposições do Estatuto que apregoam a inclusão social como valor fundamental da UFTM e incitam à necessidade de proporcionar a todos as mesmas condições e oportunidades de aprendizagem.

Na quinta parte do PDI, é abordada a Política de Atenção ao Estudante na UFTM. Conforme o documento devem ser desenvolvidas "ações e serviços direcionados ao bem estar, à segurança, à afirmação da cidadania e à autoestima do discente", a fim de garantir a permanência dos acadêmicos na instituição e também de "potencializar seu aprendizado e contribuir para sua formação profissional e humana, proporcionando isonomia de oportunidades" (UFTM, 2012, p. 13-14). Essa seção do documento continua com a apresentação de algumas ações desenvolvidas na UFTM para fortalecimento da permanência acadêmica, destacando as práticas desenvolvidas pela PROACE.

Por fim, na última subdivisão do PDI, são apresentados os Planos de Ação para o desenvolvimento institucional. Tal item, além de especificar as estratégias voltadas para o desenvolvimento da Universidade, revela as premissas (diretrizes e diagnósticos), prioridades, fontes de financiamento e os prazos de início e término dos trabalhos desenvolvidos na Instituição. Os Planos de Ação, apresentados no PDI, ciclo 2012-2016, foram construídos pelas Pró-Reitorias da UFTM, tendo por base diagnósticos situacionais elaborados por meio de pesquisa respondida pelas comunidades interna e externa da universidade. Dentre os variados diagnósticos e planos de ação, os elaborados pela PROACE, ainda que de forma sintética, são os únicos que abordam a necessidade de melhorias para o atendimento adequado das PcD. Nesse aspecto, é apontada, como de alta prioridade, a necessidade de melhorias na infraestrutura da UFTM, de modo a garantir recursos de acessibilidade nas áreas da UFTM.

Averiguou-se também que, apesar da PNAES estabelecer que a viabilização da igualdade de oportunidades/condições seja realizada por intermédio da articulação das atividades de ensino, pesquisa e extensão, as Pró-Reitorias de Ensino (PROENS), de Pesquisa e Pós-Graduação (PROPPG) e de Extensão Universitária (PROEXT) não apresentaram, explicitamente, no PDI em análise, ações e estratégias articuladas/conjuntas para inclusão dos alunos com deficiência. 


\section{c) Projeto Político Pedagógico Institucional (PPI)}

Construído coletivamente e considerado uma ferramenta de orientação das atividades acadêmicas, o PPI 2020-20246 da Universidade apresenta como finalidade reafirmar o “compromisso da instituição com o processo de permanente construção dos saberes e a formação profissional humanizada do estudante, voltada às reais necessidades da sociedade" (UFTM, 2020a, p.5).

Tal documento integra as concepções pedagógicas do estabelecimento de ensino, e, como um instrumento político, filosófico e teórico-metodológico, orienta as ações universitárias, considerando, para tanto, o processo histórico que influenciou e influencia a instituição e seu entorno. Portanto, o PPI fundamenta as práticas do tripé ensino, pesquisa e extensão, incluindo aqui as práticas pedagógicas e administrativas, fortalecendo a identidade e a missão institucional.

A análise do referido instrumento indica que a universidade ancora suas propostas formativas em princípios e valores de respeito à pessoa como ser integral. Assim, atitudes permeadas pela valorização da inclusão social, cidadania, democracia, igualdade de oportunidades e condições não são vistas como opções, mas como princípios éticos fundamentais a serem utilizados em toda e qualquer situação no âmbito da UFTM.

Ademais, destaca-se que as práticas institucionais (ações de ensino, pesquisa, extensão, gestão, administrativas) também devem se pautar em atitudes não discriminatórias, que favoreçam o pluralismo de ideias e a manifestação respeitosa de diferentes concepções e formas de pensar. Por isso, diferenças culturais, de classe social, gênero, raça, etnia, condições físicas, idade, dentre outras não deverão se constituir em empecilhos no processo ensino-aprendizagem.

Em relação à organização curricular e às práticas didático-pedagógicas, o documento indica que as mesmas deverão integrar os diferentes acadêmicos, de tal forma que estes se sintam, e realmente sejam, partes efetivas dos processos formativos. Assim, tanto os currículos quanto as metodologias devem contribuir para o fortalecimento do compromisso e do sentimento de pertencimento/integração dos acadêmicos ao curso e à Instituição.

No rol das políticas de ensino, pesquisa, pós-graduação, extensão e gestão, ressalta-se que essas, de uma forma geral, e em sintonia com a missão institucional, defendem a ampliação do quantitativo de oportunidades formativas, tendo como fundamentos a implementação de ações pautadas na centralidade do aluno, na contextualização do 
conhecimento e na articulação entre teoria e prática. Além disso, reconhecem a educação como um direito basilar e universal de todos, sendo as práticas colaborativas e participativas orientadoras de todo o processo universitário.

Ainda em relação às políticas institucionais, a minuta do PPI 2020-2024 da UFTM destaca a "necessidade de políticas e ações institucionais de suporte aos cursos para o atendimento e o acompanhamento dos estudantes com deficiência, com transtornos globais do desenvolvimento e altas habilidades ou superdotação" (UFTM, 2020a, p. 47).

Assim, o documento norteador da organização didático-pedagógica da UFTM apresenta pressupostos filosóficos e diretrizes em favor da inclusão das pessoas com deficiência, cujas ações devem ser detalhadas em resoluções institucionais relativas às políticas de ensino e de assistência estudantil.

d) Projetos Pedagógicos de Curso (PPC)

O Projeto Pedagógico de Curso (PPC) é um documento que expressa as concepções de ensino e aprendizagem de um determinado curso, bem como sua visão de mundo e seus valores. Deste modo, o PPC de um curso de graduação é sua "coluna vertebral" e tem como objetivo fundamental concretizar um ensino de qualidade, com mais autonomia pedagógica para atender suas demandas (UFTM, 2020b).

O processo de construção e atualização dos PPC de graduação é assessorado pela Divisão de Apoio Técnico-Pedagógico (DATP), órgão pedagógico da PROENS. A equipe da DATP elaborou a primeira versão do Guia para Elaboração e Atualização de Projetos Pedagógicos de Cursos de Graduação da UFTM no ano de 2011, documento que é atualizado periodicamente e se baseia nas concepções filosóficas, pedagógicas e teórico-metodológicas da instituição, explicitadas no PPI, bem como na legislação educacional vigente e no Instrumento de Avaliação do Sistema Nacional de Avaliação da Educação Superior - Sinaes. As diretrizes contidas nesse documento têm reflexo direto na organização dos PPC dos cursos, ganhando materialidade na prática pedagógica.

À luz do Guia e visando conhecer o que consta nos PPC dos cursos de graduação, sobre a inclusão dos alunos com deficiência, foram analisados vinte e dois ${ }^{7} \mathrm{PPC}$ dos cursos de graduação das seguintes grandes áreas, ofertados no campus sede da UFTM: Ciências da Saúde (Biomedicina, Enfermagem, Medicina, Educação Física-bacharelado, Terapia Ocupacional e Serviço Social), Ciências Tecnológicas e Exatas (Engenharias de Alimentos, Ambiental, Civil, Elétrica, Mecânica, de Produção e Química) e Ciências da Educação, 
Humanas e Sociais (Ciências Biológicas, Educação no Campo, Física, Geografia, História, Matemática, Química, Psicologia e Serviço Social). De forma geral, todos os PPC apresentam as categorias "cidadania e respeito às diferenças", "tratamento justo e respeitoso ao ser humano e à vida", e "inclusão social” como sendo princípios que devem alicerçar o pensamento e as práticas do curso.

Outro elemento comum presente nos PPC é o item "Administração acadêmica do curso", que tem a "Assistência estudantil" como parte integrante. Este tópico se estrutura no direito do aluno a recursos e serviços educacionais especializados, essenciais para a concretização da democratização e promoção da equidade no espaço universitário, principalmente no que diz respeito ao acesso, participação e aprendizagem de pessoas com deficiência, transtornos globais do desenvolvimento, altas habilidades e superdotação.

Para este item, "Administração acadêmica do curso", o setor de assessoramento pedagógico da UFTM propõe, ao realizar as análises dos PPC, que todos descrevam as atribuições e políticas vigentes da PROACE, uma vez que se aplicam aos alunos dos cursos de graduação, indistintamente. Também solicita que os cursos descrevam suas propostas internas de inclusão, demonstrando o que a coordenação do curso e o corpo docente se propõem a fazer para promover a aprendizagem dos alunos com deficiência e necessidades educacionais especiais.

Nesse sentido, dois $\operatorname{cursos}^{8}$ da área da saúde não apresentaram nos seus PPC outros pontos concernentes à inclusão, a não ser essa descrição geral sobre as ações da PROACE.

$\mathrm{Na}$ parte relativa à "Concepção do Curso", no subitem "Fundamentação TeóricoMetodológica", a preocupação referente ao tema inclusão foi encontrada em seis PPC: um relativo ao curso de Licenciatura e cinco cursos da área de Engenharia ${ }^{9}$. Nestes verificou-se a abordagem da formação integral, de forma inclusiva e democrática.

Ainda no item "Concepção do Curso", subitem "Competências e Habilidades", dois PPC da área da saúde ${ }^{10}$ revelaram uma preocupação referente à inclusão social, a partir da busca pelo desenvolvimento de profissionais com posicionamento crítico e cidadão, no aspecto da saúde e da qualidade de vida das pessoas com necessidades especiais, a partir da compreensão de questões sociais e culturais das relações humanas.

Em relação ao item "Metodologias do Ensino e da Aprendizagem", três PPC da área de Licenciatura ${ }^{11}$ demonstraram preocupação com a temática. Neles são encontradas reflexões sobre o modelo tradicional de educação, no sentido de se pensar novas formas de avaliação 
discente, principalmente na proposição de novas metodologias de ensino e aprendizagem. Assim, mencionam também a importância de se ter políticas e ações institucionais de suporte aos cursos para acompanhamento e atendimentos das demandas dos alunos com necessidades específicas, a fim de ampliar os espaços inclusivos na universidade.

Quanto ao item "Abrangência do Curso no Ensino, Pesquisa e Extensão", a preocupação relativa às necessidades específicas foi verificada em cinco cursos da área da saúde e em quatro cursos de licenciaturas ${ }^{12}$. Assim, nesses documentos foram encontrados alguns pontos, tais como: o incentivo às atividades de inclusão universitária, o desenvolvimento e implantação de projetos nas áreas de acessibilidade e inclusão social, e a garantia de acesso ao ensino de qualidade e inclusivo.

No item do PPC "Histórico do curso e sua justificativa social e econômica", há um curso da área da saúde que justifica a necessidade da inclusão como algo intrínseco ao próprio curso; e dois cursos de licenciatura que reivindicaram em seus PPC mais ações institucionais voltadas à infraestrutura, acolhimento e assistência estudantil, formação docente, nivelamento acadêmico, entre outras questões que se relacionam com a inclusão. (Terapia Ocupacional, Física e Ciências Biológicas).

Quanto à organização curricular, destacamos no Quadro 1 as disciplinas que os cursos ofertam com temáticas ligadas à inclusão. Ressaltamos que na UFTM existem três naturezas de disciplinas, a saber, disciplinas obrigatórias, sendo aquelas cuja integralização de carga horária é imprescindível à conclusão do curso; disciplinas eletivas, sendo aquelas que pertencem a um rol de opções destinadas à livre escolha dos alunos (embora possam escolher estas disciplinas, os alunos precisam cursar a carga horária de eletivas pré-determinada pelo curso para se formarem); disciplinas optativas, que são aquelas que os alunos podem cursar em cursos diversos para enriquecimento curricular, ou seja, a carga horária dessas disciplinas não é exigida para conclusão da graduação. Assim, apresentamos as disciplinas voltadas à temática inclusão nos cursos de graduação do campus sede da UFTM:

QUADRO 1 - Disciplinas relacionadas à inclusão nos cursos de graduação do campus sede da UFTM

\begin{tabular}{|l|l|c|}
\hline \multicolumn{1}{|c|}{ CURSO } & \multicolumn{1}{|c|}{$\begin{array}{c}\text { DISCIPLINA SOBRE O } \\
\text { TEMA INCLUSÃO }\end{array}$} & $\begin{array}{c}\text { NATUREZA DA } \\
\text { DISCIPLINA } \\
\text { HORÁRIA CARA }\end{array}$ \\
\hline Biomedicina & Libras & $\begin{array}{c}\text { Optativa - CH } \\
\text { indeterminada }\end{array}$ \\
\hline Enfermagem & Libras & Optativa - CH \\
\hline
\end{tabular}




\begin{tabular}{|c|c|c|}
\hline & & indeterminada \\
\hline \multirow{2}{*}{ Serviço Social } & Libras & $\begin{array}{c}\text { Obrigatória }\left(8 .^{\circ} \text { período }\right)- \\
30 \mathrm{~h}\end{array}$ \\
\hline & $\begin{array}{l}\text { Legislações específicas da } \\
\text { Educação Especial }\end{array}$ & Eletiva $-30 \mathrm{~h}$ \\
\hline \multirow{4}{*}{ Terapia Ocupacional } & Análise institucional & $\begin{array}{c}\text { Obrigatória }\left(2 .{ }^{\circ} \text { período }\right)- \\
30 \mathrm{~h}\end{array}$ \\
\hline & $\begin{array}{l}\text { Noções básicas de orientação e } \\
\text { mobilidade }\end{array}$ & Eletiva $-30 \mathrm{~h}$ \\
\hline & Tecnologia Assistiva I & $\begin{array}{c}\text { Obrigatória }\left(5 .^{\circ} \text { período }\right)- \\
30 \mathrm{~h}\end{array}$ \\
\hline & Tecnologia Assistiva II & $\begin{array}{c}\left.\text { Obrigatória (6. }{ }^{\circ} \text { período }\right)- \\
30 \mathrm{~h}\end{array}$ \\
\hline \multirow{4}{*}{ Psicologia } & Psicologia e Inclusão & $\begin{array}{l}\text { Obrigatória }\left(6 .^{\circ} \text { período }\right)- \\
60 \mathrm{~h}\end{array}$ \\
\hline & Psicomotricidade & $\begin{array}{c}\text { Obrigatória }\left(3 .^{\circ} \text { período }\right)- \\
60 \mathrm{~h}\end{array}$ \\
\hline & Psicologia e Inclusão & $\begin{array}{c}\text { Obrigatória }\left(6 .^{\circ} \text { período }\right)- \\
60 \mathrm{~h}\end{array}$ \\
\hline & $\begin{array}{l}\text { Legislações específicas da } \\
\text { educação especial }\end{array}$ & Eletiva $-30 \mathrm{~h}$ \\
\hline Medicina & Libras & Optativa - não definida \\
\hline Educação Física & Educação Física Adaptada & $\begin{array}{c}\left.\text { Obrigatória ( } 7 .^{\circ} \text { período }\right)- \\
60 \mathrm{~h}\end{array}$ \\
\hline \multirow{2}{*}{$\begin{array}{l}\text { Licenciatura em Ciências } \\
\text { Biológicas }\end{array}$} & História e Política Educacional & $\begin{array}{c}\text { Obrigatória }\left(5 .^{\circ} \text { período }\right)- \\
60 \mathrm{~h}\end{array}$ \\
\hline & Libras & $\begin{array}{c}\text { Obrigatória }\left(7 .^{\circ} \text { período }\right)- \\
30 \mathrm{~h}\end{array}$ \\
\hline $\begin{array}{l}\text { Licenciatura em Educação } \\
\text { do Campo }\end{array}$ & $\begin{array}{l}\text { Educação Inclusiva e Língua } \\
\text { Brasileira de Sinais }\end{array}$ & $\begin{array}{c}\text { Obrigatória }\left(8 .^{\circ} \text { período }\right)- \\
60 \mathrm{~h}\end{array}$ \\
\hline \multirow{5}{*}{ Licenciatura em Física } & História e Política da Educação & $\begin{array}{c}\text { Obrigatória }\left(7 .^{\circ} \text { período }\right)- \\
60 \mathrm{~h}\end{array}$ \\
\hline & $\begin{array}{l}\text { Orientação e estágio curricular } \\
\text { supervisionado C }\end{array}$ & $\begin{array}{c}\text { Obrigatória }\left(8 .^{\circ} \text { período }\right)- \\
180 \mathrm{~h} \\
\end{array}$ \\
\hline & $\begin{array}{l}\text { Modalidades de educação e } \\
\text { ensino de ciências }\end{array}$ & Eletiva $-90 \mathrm{~h}$ \\
\hline & $\begin{array}{l}\text { Educação inclusiva e ensino de } \\
\text { ciências }\end{array}$ & Eletiva $-90 \mathrm{~h}$ \\
\hline & Libras & $\begin{array}{c}\text { Obrigatória }\left(8 .^{\circ} \text { período }\right)- \\
30 \mathrm{~h} \\
\end{array}$ \\
\hline \multirow{2}{*}{ Licenciatura em Geografia } & $\begin{array}{l}\text { Orientação e estágio curricular } \\
\text { supervisionado II }\end{array}$ & $\begin{array}{c}\left.\text { Obrigatória (6. }{ }^{\circ} \text { período }\right)- \\
120 \mathrm{~h} \\
\end{array}$ \\
\hline & Libras & $\begin{array}{l}\text { Obrigatória }\left(7 .^{\circ} \text { período }\right)- \\
30 \mathrm{~h}\end{array}$ \\
\hline Licenciatura em História & Libras & $\begin{array}{c}\text { Obrigatória }\left(7 .^{\circ} \text { período }\right)- \\
30 \mathrm{~h}\end{array}$ \\
\hline Licenciatura em & História e Política Educacional & Obrigatória $\left(5 .^{\circ}\right.$ período $)-$ \\
\hline
\end{tabular}




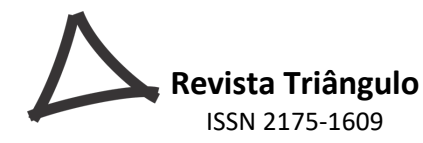

\begin{tabular}{|c|c|c|}
\hline \multirow[t]{3}{*}{ Matemática } & & $60 \mathrm{~h}$ \\
\hline & Libras & $\begin{array}{c}\text { Obrigatória }\left(8 .^{\circ} \text { período }\right)- \\
30 \mathrm{~h}\end{array}$ \\
\hline & Inclusão e Educação Matemática & $\begin{array}{c}\text { Obrigatória }\left(8 .^{\circ} \text { período }\right)- \\
75 \mathrm{~h}\end{array}$ \\
\hline \multirow{3}{*}{ Licenciatura em Química } & $\begin{array}{l}\text { Educação Especial e Inclusiva no } \\
\text { Ensino de Química }\end{array}$ & Eletiva $-120 \mathrm{~h}$ \\
\hline & Libras & $\begin{array}{c}\text { Obrigatória }\left(7 .^{\circ} \text { período }\right)- \\
30 \mathrm{~h}\end{array}$ \\
\hline & $\begin{array}{l}\text { Produção de Material Didático } \\
\text { Adaptado para Deficientes } \\
\text { Visuais }\end{array}$ & Eletiva $-120 \mathrm{~h}$ \\
\hline $\begin{array}{l}\text { Engenharias de: Alimentos, } \\
\text { Ambiental, Civil, Elétrica, } \\
\text { Mecânica, de Produção, } \\
\text { Química. }\end{array}$ & Libras & $\begin{array}{l}\text { Eletiva }-30 \mathrm{~h} \text { (por } \\
\text { Engenharia) }\end{array}$ \\
\hline
\end{tabular}

Fonte: Divisão de Apoio Técnico-Pedagógico (DATP). Pró-reitoria de Ensino (PROENS). UFTM, 2020.

Depreende-se do estudo a necessidade de maior quantidade de componentes curriculares e conteúdos ligados à inclusão na organização didático-pedagógica dos cursos de graduação, bem como de proporcionar ao estudante com deficiência condições equitativas para o seu desenvolvimento acadêmico.

\section{CONCLUSÃO}

Em meio a políticas e legislações educacionais que orientam as ações voltadas para as pessoas com deficiência no âmbito do ensino superior, as IFES vêm buscando formas de garantir o acesso e a permanência com qualidade destas pessoas nas instituições de ensino, intentando superar os limites que precisam ser analisados e discutidos, a fim de que o direito à educação seja efetivo para todos.

Com a universalização do acesso aos cursos de graduação, a UFTM, apesar de todos os avanços na busca de condições adequadas para o desenvolvimento integral dos diferentes acadêmicos, dentre eles as pessoas com deficiência, necessita que sejam ampliados os seus recursos de natureza humana, orçamentária, tecnológica e físico-estruturais. Destaca-se que nas questões estruturais são imprescindíveis maiores investimentos em recursos de acessibilidade arquitetônica em todas as áreas da universidade, adaptando as já existentes e proporcionando espaços adequados para atendimento dos estudantes. 
Torna-se essencial, também, a ampliação de recursos financeiros destinados a mobiliários, materiais didático-pedagógicos e outros ligados à assistência estudantil de forma geral, além da implementação de ações voltadas ao envolvimento comunitário. Ressalta-se, ainda, a fundamental importância de se ampliar a equipe multiprofissional para o atendimento especial das pessoas com deficiência.

Ademais, a pesquisa aponta a necessidade de ampliação da intersetorialidade entre os diversos órgãos da universidade, na busca de redes de apoio internas e externas à instituição visando ao atendimento dos alunos com deficiência e ao aprofundamento das discussões sobre a construção de aprendizagens desses educandos nos diversos espaços educativos.

É preciso, essencialmente, que se dê maior ênfase nos documentos institucionais às ações voltadas para a inclusão dos alunos com deficiência, a fim de se nortear e fazer cumprir mecanismos que garantam a todos, sem exceção, acessibilidade ao ensino de qualidade. $\mathrm{O}$ desenvolvimento do processo educacional deve garantir que todos esses estudantes tenham o direito não apenas de ingressar no ensino superior, mas de permanecerem nele com sucesso, evitando-se a retenção e a evasão dos mesmos.

É primordial que se garanta a esses alunos o direito de aprender e, para isso, além da sensibilização e conscientização dos atores envolvidos, é preciso desenvolver um maior número de ações institucionais de suporte aos cursos de graduação para o atendimento e o acompanhamento das pessoas com deficiência. A UFTM deve ampliar, em sua organização curricular, conteúdos voltados para a atenção à diversidade, contemplando conhecimentos sobre as especificidades pedagógicas voltadas aos alunos deficientes.

Nesse sentido, sugere-se que seja intensificado o debate sobre a inclusão de alunos com deficiência em toda a universidade, aprofundando estudos por meio da criação de uma política institucional de formação de professores. Assim, à luz de referenciais teóricos sobre as inúmeras deficiências, estudos pedagógicos e discussões junto a todos os profissionais e comunidade acadêmica, deve-se envolver, em especial, as pessoas com deficiência, a fim de que seus anseios, dificuldades, lutas e ideais sejam ouvidos e que eles sejam respeitados como sujeitos participativos do processo ensino-aprendizagem.

Espera-se que este estudo contribua para as pesquisas acerca da inclusão dos alunos com deficiência no ensino superior brasileiro e que contribua com as políticas públicas para a inclusão dos mesmos nos cursos de graduação. Pretende-se que suscite na UFTM continuadas reflexões sobre a importância de se universalizar, para as pessoas com deficiência, o acesso ao 


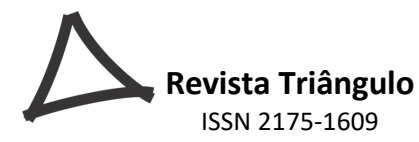

ensino de qualidade, via práticas educativas que respeitem a diversidade humana em todas as suas dimensões.

\begin{abstract}
${ }^{1}$ Anteriormente denominada Faculdade de Medicina do Triângulo Mineiro - FMTM, transformada no ano de 2005 em Universidade Federal do Triângulo Mineiro, a UFTM é uma Instituição Federal de Ensino Superior, constituída sob a forma de autarquia, vinculada ao Ministério da Educação. Com sede na cidade de UberabaMG e com um campus no município de Iturama-MG, a UFTM oferta cursos de diversas áreas do conhecimento, atualmente contando com um alunado de, aproximadamente, 7.000 (sete mil) estudantes, nos cursos de graduação, pós-graduação e educação profissionalizante. A UFTM oferta 29 cursos de graduação, sendo: 26 cursos no Campus Sede (Uberaba):Biomedicina, Lic. Ciências Biológicas, Educação Física, Enfermagem, Engenharia Ambiental, Engenharia Civil, Engenharia de Alimentos, Engenharia de Produção, Engenharia Elétrica, Engenharia Mecânica, Engenharia Química, Lic. Física, Fisioterapia, Lic. Geografia, Lic. História, Lic. Letras - Português e Espanhol, Lic. Letras - Português e Inglês, Lic. Educação do Campo, Lic. Matemática, Medicina, Nutrição, Psicologia, Lic. Química, Serviço Social, Terapia Ocupacional e Lic. Pedagogia, curso criado recentemente na modalidade EaD; e 03 no Campus Iturama-MG: Agronomia, Lic. Ciências Biológicas e Lic. Química.
\end{abstract}

2 São as atitudes das pessoas diante da deficiência/NEE, como consequência da falta de informação e preconceito, o que acarreta discriminação e mais preconceito, causando exclusão.

${ }^{3}$ O Programa Nacional de Assistência Estudantil - PNAES, criado em 2010 pelo Ministério da Educação, tem como finalidade ampliar as condições de permanência dos jovens na educação superior pública federal.

${ }^{4} \mathrm{O}$ Programa de Acessibilidade na Educação Superior (Incluir) propõe ações que garantem o acesso pleno de pessoas com deficiência às IFES, com o principal objetivo de fomentar a criação e a consolidação de núcleos de acessibilidade ao ensino superior, os quais respondem pela organização de ações institucionais que garantam a integração de pessoas com deficiência à vida acadêmica, eliminando barreiras comportamentais, pedagógicas, arquitetônicas e de comunicação.

${ }^{5}$ Para a elaboração deste trabalho de pesquisa, analisou-se o PDI 2012-2016, uma vez que a versão mais recente do documento ainda não foi apreciada pelo Conselho Superior (CONSU) da Universidade.

${ }^{6}$ A nova versão do PPI da UFTM está em fase de minuta, aguardando aprovação do Conselho Universitário CONSU, porém foi apresentada e aprovada nos seguintes conselhos superiores da instituição: Conselho de Ensino - COENS, Conselho de Pesquisa e Pós-Graduação (COPPG) e Conselho de Extensão Universitária COEXT.

${ }^{7}$ Dos 26 cursos de graduação da UFTM ofertados no campus sede da UFTM, foram analisados os PPC de 22 cursos, pois 03 documentos encontravam-se em fase de reestruturação: Bacharelado em Nutrição (área Ciências da Saúde), Licenciatura em Letras Português/Inglês e Licenciatura em Letras Português/Espanhol); quanto ao curso de Pedagogia, não foi feita a análise técnica do documento, considerando que trata-se de um curso recémcriado na instituição. Os 03 últimos cursos citados referem-se à área Ciências da Educação, Humanas e Sociais.

${ }^{8}$ Cursos de Graduação em Medicina e Biomedicina.

9 Licenciatura em Química, Engenharia Mecânica, Engenharia Civil, Engenharia Química, Engenharia Ambiental e Engenharia de Alimentos.

${ }^{10}$ Bacharelado em Educação Física e Terapia Ocupacional.

${ }^{11}$ Licenciaturas em Matemática, Ciências Biológicas e Física.

12 Enfermagem, Fisioterapia, Terapia Ocupacional, Biomedicina, Nutrição. Cursos de Licenciatura em Geografia, História, Letras Port./Inglês e Letras Port./Espanhol.

${ }^{13}$ Na UFTM há três naturezas de disciplinas: obrigatórias, que devem ser cursadas pelos alunos da forma como constam nas matrizes curriculares; eletivas, que devem ser cursadas a partir de escolha livre dos alunos, 

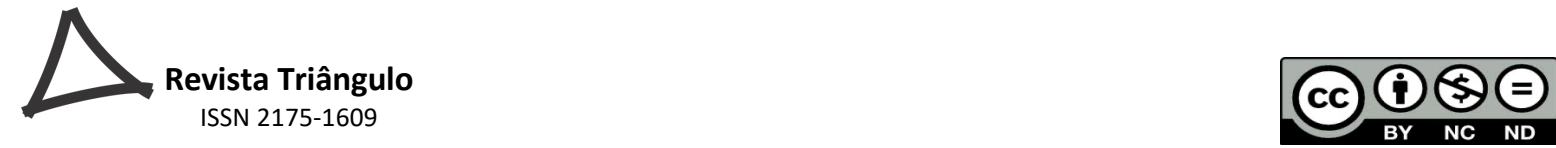

conforme rol de opções fornecido pelos cursos; optativas, que pertencem a cursos diversos e que não integralizam a carga horária dos alunos, servindo para enriquecimento curricular.

\section{REFERÊNCIAS}

BATISTA, D. de M. Avaliação técnica do trabalho desenvolvido no setor de acessibilidade, da assistência estudantil, da Universidade Federal do Triângulo Mineiro: estudo de caso. 2018. 125 f. Dissertação (Mestrado Profissional em Administração Pública) Universidade Federal do Triângulo Mineiro, Uberaba, 2018.

BRASIL, Política Nacional de Educação Especial na Perspectiva da Educação Inclusiva. Brasília: MEC/SEESP, 2007. Disponível em: http://portal.mec.gov.br/index.php?option=com_docman\&view=download\&alias $=424$ cartilha-c\&category_slug=documentos-pdf\&Itemid=30192. Acesso em: 15 ago. 2020.

BRASIL. Decreto n. ${ }^{\circ}$ 6.096/2007. Institui o Programa de Apoio a Planos de Reestruturação e Expansão das Universidades Federais - REUNI, 2007a. Disponível em: http://www.planalto.gov.br/ccivil_03/_ato2007-2010/2007/decreto/d6096.htm. Acesso em: 15 ago. 2020.

BRASIL. Sinopse da educação superior. 2007b. Disponível em: $<$ http://portal.inep.gov.br/superior-censosuperior-sinopse>. Acesso: 28 out. 2020.

BRASIL. Decreto n. ${ }^{\circ}$ 7.234, de 19 de julho de 2010. Programa Nacional de Assistência Estudantil (PNAES), 2010. Disponível em: http://www.planalto.gov.br/ccivil_03/_ato20072010/2010/decreto/d7234.htm. Acesso em: 15 ago. 2020.

UNIVERSIDADE FEDERAL DO TRIÂNGULO MINEIRO. Plano de Desenvolvimento Institucional da UFTM: PDI 2012/2016. Uberaba, MG: UFTM, 2012. Disponível em: http://www.uftm.edu.br/proplan/planejamento-e-desenvolvimento/planejamentoestrategico/pdi/pdi. Acesso em: 15 ago. 2020.

UNIVERSIDADE FEDERAL DO TRIÂNGULO MINEIRO. Estatuto da Universidade Federal do Triângulo Mineiro - UFTM. Uberaba, MG: UFTM, 2013.

Disponível em: http://www.uftm.edu.br/proplan/regulamentacao-e-normatizacao/estatuto. Acesso em: 15 ago. 2020.

UNIVERSIDADE FEDERAL DO TRIÂNGULO MINEIRO. Pró-Reitoria de Planejamento. Regimento Interno da PROACE. Uberaba, MG: UFTM, 2016. Disponível em: http://www.uftm.edu.br/proace/legislacao

Acesso em: 18 ago. 2020.

UNIVERSIDADE FEDERAL DO TRIÂNGULO MINEIRO. Minuta do Projeto Pedagógico Institucional da UFTM: PPI 2020/2024. Uberaba, MG: UFTM, 2020a.Disponível em: http://www.uftm.edu.br/proens/apoio-tecnico-pedagogico/comite-dereestruturacao-do-ppi. Acesso em: 20 ago. 2020. 
UNIVERSIDADE FEDERAL DO TRIÂNGULO MINEIRO. Guia para Elaboração e Atualização de Projetos Pedagógicos de Cursos de Graduação da UFTM. Uberaba, MG: UFTM, 2020b. Disponível em: http://www.uftm.edu.br/proens/apoio-tecnicopedagogico/formularios-e-orientacoes. Acesso em: 24 ago. 2020 